\title{
TITLE:
}

\section{Propose Alternative Design Criteria for Dowel Type Joint with CLT}

AUTHOR(S):

Nakashima, Shoichi; Kitamori, Akihisa; Mori, Takuro; Komatsu, Kohei

\section{CITATION:}

Nakashima, Shoichi ...[et al]. Propose Alternative Design Criteria for Dowel Type Joint with CLT. RILEM Bookseries 2014, 9: 739-748

\section{ISSUE DATE:}

2014

URL:

http://hdl.handle.net/2433/193000

\section{RIGHT:}

The final publication is available at Springer via http://dx.doi.org/10.1007/978-94-0077811-5_66.; This is not the published version. Please cite only the published version.; この 論文は出版社版でありません。引用の際には出版社版をご確認ご利用ください。 


\title{
PROPOSE ALTERNATIVE DESIGN CRITERIA FOR DOWEL TYPE JOINT WITH CLT
}

\author{
Shoichi Nakashima, Akihisa Kitamori, Takuro Mori, and Kohei Komatsu
}

Research Institute for Sustainable Humanosphere, Kyoto University, Gokasho, Uji, Kyoto, 611-0011, Japan.e-mail: s-nakashima@rish.kyoto-u.ac.jp

\begin{abstract}
The load carrying capacity of dowel type joint in Cross Laminated Timber (CLT) was derived based on the Johansen's yield model. The steel plate inserted drift pin joint with CLT (5 layered; thickness of laminae were same in one CLT, all of laminae were orthogonally arranged) was chosen as the specimen. Stiffness and nonlinear load - deformation relationships were calculated by numerical analysis using Rigid Body Spring Model (RBSM). Estimation showed the good agreement with the tensile test results on the joints.
\end{abstract}

\section{Introduction}

Cross Laminated Timber (CLT) is especially expected in Japan as a new material for the structural wall panel and/or floor which might promote the usage of local low grade Japanese cedar.

We chose the dowel type joint as the connectors to fix wall legs because it has high stiffness and strength and ductility.

For the drift pin joint in solid timber or glulam the criteria for the yield load depends on the Johansen's Yield Model and stiffness depends on the beam on elastic foundation theory. In this paper, load carrying capacity is derived based on Johansen's theory and stiffness were estimated by the numerical analysis with Rigid Body Spring Model (RBSM) based on the Winkler's foundation model[1, 2]. 


\section{Load Carrying Capacity}

\section{Assumption}

Load carrying capacity by Johansen's Yield Model for the six layers CLT was reported by Uibel et al [3]. Here, newly 5 layers CLT was picked up. Model consists of steel plate, drift pin, and CLT (5 layered; thickness of laminae were same in one CLT, all of laminae were orthogonally arranged). It was assumed that the perfectly plastic relationships for the materials could be held good to decide the load carrying capacity $\left(p_{y}\right)$. Fig.2 shows the possible yielding models for deriving $p_{\mathrm{y}}$. To derive the tensile performance of drift pin joint of CLT, equilibrium of the loads is drawn such as shown in Fig.2.

Load carrying capacity was derived using the diameter $(d)$, length $(l)$ and bending strength $(F)$ of drift pin and density $(\rho)$ of timber. In practice, the diameter of drift pin is the region of $10-20 \mathrm{~mm}$. Therefore in such region, load carrying capacity will be decided by Mode2.2 deformation in dFig.2.

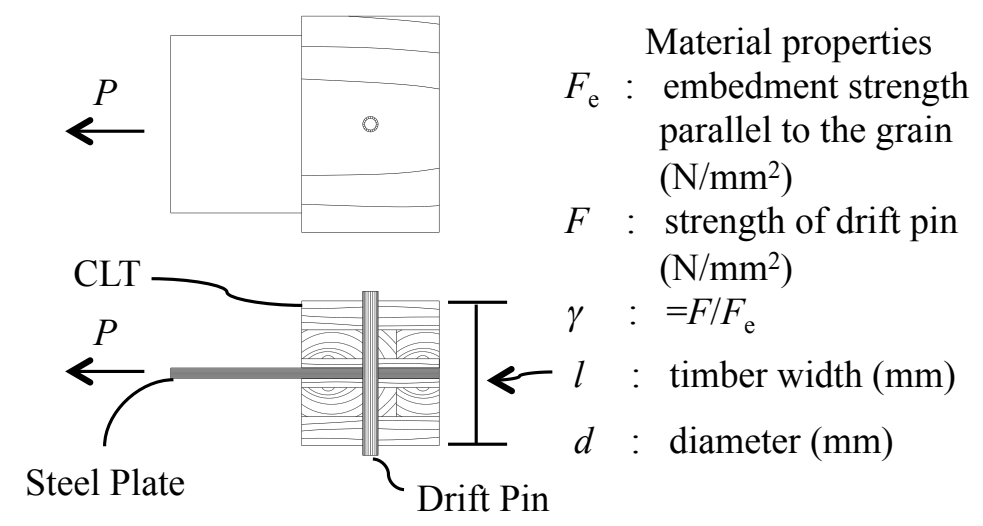

Fig. 1 Concept of joint and defenition of material properties.

Load carrying capacity $\left(p_{\mathrm{y}}\right)$ of the CLT dowel type joint with slotted in steel plate should be estimated by following equation.

$$
p_{y}=C \cdot F_{e} \cdot d \cdot l
$$

where,

$C$ : coefficient depends on joint configuration and failure mode shown in Fig.2

$F_{\mathrm{e}}$ : basic bearing strength of timber (surface layer) $\left(\mathrm{N} / \mathrm{mm}^{2}\right)$

$d$ : diameter of fastener ( $\mathrm{mm}$ )

$l$ : effective length of fastener in CLT panel 


\section{Coefficient C}

Coefficient $C$ should be determined from the minimum value of following equation;

$$
C=\left\{\begin{array}{lc}
\frac{4}{5} & \text { Mode1 } \\
\sqrt{\frac{58}{25}+\frac{8}{3} \gamma\left(\frac{d}{l}\right)^{2}}-\frac{6}{5} & \text { Mode2.2 } \\
\frac{d}{l} \sqrt{\frac{8}{3} \gamma} & \text { Mode3.1 } \\
\sqrt{-\frac{1}{100}+\frac{4}{3} \gamma\left(\frac{d}{l}\right)^{2}}+\frac{1}{10} & \text { Mode3.2 } \\
\sqrt{\frac{4}{25}+\frac{8}{3} \gamma\left(\frac{d}{l}\right)^{2}}-\frac{1}{5} & \text { Mode3.3 }
\end{array}\right.
$$

where,

$\gamma$ : ratio of basic material strength of fastener and that of basic bearing strength of main member $\left(F / F_{\mathrm{e}}\right)$

$F$ : basic material strength of fastener $\left(\mathrm{N} / \mathrm{mm}^{2}\right)$

$F_{\mathrm{e}}$ : bearing strength of timber (surface layer) $\left(\mathrm{N} / \mathrm{mm}^{2}\right)$

Equation(2) stands on the following assumptions of equation(3);

$\left\{\begin{array}{l}t_{1}=t_{2}=2 t_{3}=t=\frac{l}{5} \\ f_{1}=2 f_{2}=f_{3}=F_{e}\end{array}\right.$

where,

$t_{1}$ : thickness of first layer (surface layer) $(\mathrm{mm})$

$t_{2}$ : thickness of second layer (middle inner layer) $(\mathrm{mm})$

$t_{3}$ : thickness of third layer (central layer) $(\mathrm{mm})$

$f_{1}$ : bearing strength of first layer (surface layer) $\left(\mathrm{N} / \mathrm{mm}^{2}\right)$

$f_{2}$ : bearing strength of second layer (middle inner layer) $\left(\mathrm{N} / \mathrm{mm}^{2}\right)$

$f_{3}$ : bearing strength of third layer (central layer) $\left(\mathrm{N} / \mathrm{mm}^{2}\right)$

The assumption of equation(3) indicates (a) the thickness of each layer is same (b) bearing strength of perpendicular to the grain layer is the half of that of parallel to the grain layer. From this assumption, Mode 2.1 of Fig. 2 cannot stand. 

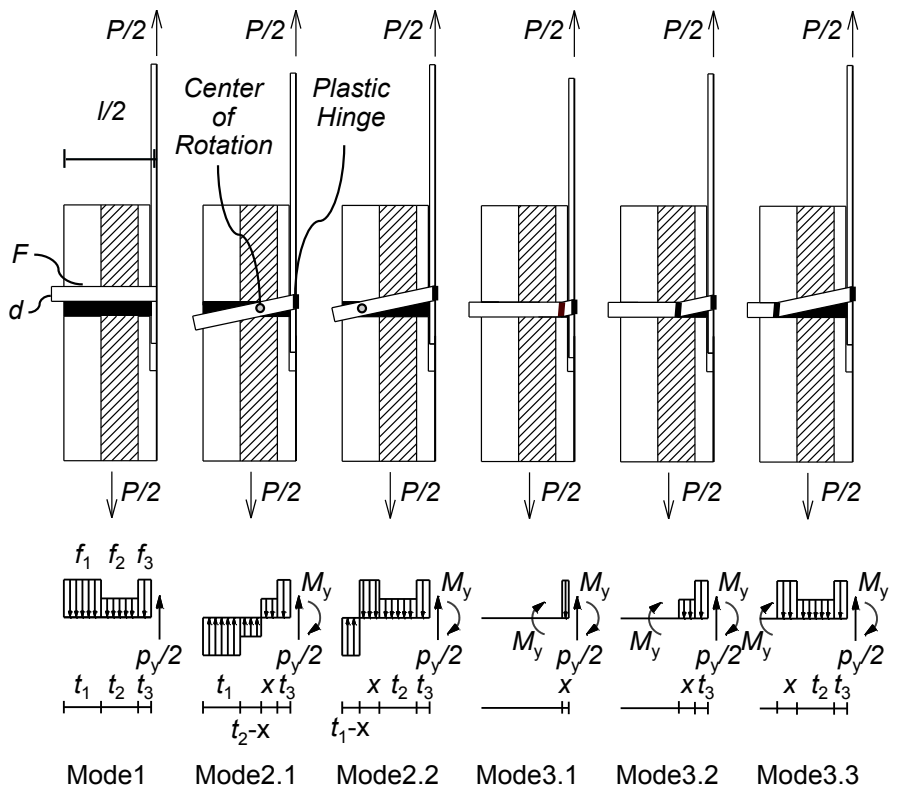

Fig.2 Possible yielding models based on equilibrium of the loads.

\section{Figure for Load Carrying Capacity}

Fig. 3 shows the relationship between load carrying capacity divided by square of diameter of fastener $\left(p_{\mathrm{y}} / d^{2}\right)$ and ratio of length and diameter of fastener $(l / d)$, which were shown in Eq.1.

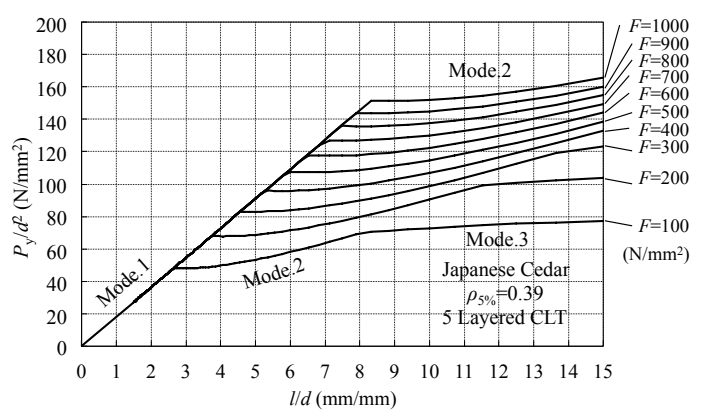

Fig. 3 Relationships (Py/d2-1/d) for the Load Carrying Capacity $\left(p_{y}\right)$. 


\section{Determination of Load-Deflection Curve of Dowel - Type Joints}

\section{Analysis}

It is important for structural design to determine the load $(P)$ - deformation $(\delta)$ curve of CLT dowel type joint to obtain the stiffness, yield load and the other characteristic values.

The stiffness of dowel type joints is usually determined by the theory of the beam on elastic foundation, in which an assumption of homogeneous material is used to derive the equation. Here, we dared to determine not only the stiffness but also the shape of curve by simulating the situation of beam on nonlinear multi-layered foundation as shown in Fig.4. This model called RBSM (Rigid Body Spring Model) developed by Kawai [6] and applied to bolted joint and drift pin joint in glulam by Tsujino, et al. [7].

In comparison with past usual 2D FEM model with Winklear's foundation model, each element is replaced by rigid body and normal, shear, and rotation spring at both nodal points(shown in Fig.4). The foundation consists of normal spring is also replaced by combination of normal and rotation springs.

The behavior of the dowel itself is assumed as a nonlinear. The stress $(\sigma)-$ strain $(\varepsilon)$ relationship of the dowel is expressed with three springs as in Fig.4 and they are expressed in Eq.4 according to Kawai [6] and Tsujino [7].

$$
\begin{aligned}
& k_{n}=\frac{2 E A}{l_{1}+l_{2}}, k_{s}=\frac{2 E A}{\left(l_{1}+l_{2}\right)(1+\mu)}, k_{m}=\frac{2 E I}{l_{1}+l_{2}} \\
& M_{y}=\frac{\sigma I}{d} \\
& k_{m 2}=\alpha k_{m}, k_{m 3}=\beta k_{m}
\end{aligned}
$$

where;

$E=205000 \mathrm{~N} / \mathrm{mm}^{2}$ (modulus of elasticity of steel beam)

$\mathrm{A}=\pi d^{2} / 4 \mathrm{~mm}^{2}$ (cross section area of steal beam)

$l_{1}=$ length of the element of the model $1(\mathrm{~mm})$

$l_{2}=$ length of the element of the model $2(\mathrm{~mm})$

$\mu=0.3$ (Poisson's ratio of steel)

$d=$ diameter of steel beam $(\mathrm{mm})$

$\alpha=k_{\mathrm{m} 2} / k_{\mathrm{m}}=0.035, \beta=k_{\mathrm{n} 3} / k_{\mathrm{m}}=0.02$

$k_{\mathrm{m}}, k_{\mathrm{m} 2}, k_{\mathrm{m} 3}=$ initial, second and third rotational stiffness (Nmm/rad) 
$k_{\mathrm{n}}=$ initial normal stiffness $(\mathrm{N} / \mathrm{mm})$

$k_{\mathrm{s}}=$ initial shear stiffness $(\mathrm{N} / \mathrm{mm})$

$\sigma=580 \mathrm{~N} / \mathrm{mm}^{2}$ (proportional limit strength of steel beam)

$\sigma_{2}=750 \mathrm{~N} / \mathrm{mm}^{2}$ (strength of steel beam)

here, $\sigma, \sigma_{2}, \alpha$ and $\beta$ are obtained by three point bending test of fasteners as shown in the sub-figure in Fig.4.

Timbers that are oriented in parallel and perpendicular to the grain direction are also assumed as a tri-linear Winkler - type foundation that generates restoring stress in response to the deflection of the beam. Them bearing stress $(\sigma)-\mathrm{em}$ bedment $(\delta)$ relationship is obtained by embedment tests for parallel and perpendicular to the grain direction. The spring constants of model expressed in equation (8), according to Tsujino [7]

For $0^{\circ}$ direction layers;

$$
K_{h}=k_{0} l_{i}, K_{r}=\frac{k_{0} l_{i}^{3}}{12}
$$

For $90^{\circ}$ direction layers;

$$
K_{h}=k_{90} l_{i}, K_{r}=\frac{k_{90} l_{i}^{3}}{12}
$$

where;

$$
\begin{aligned}
& l_{\mathrm{i}}=\text { length of element }(\mathrm{mm}) \\
& k_{0}=35.23 \mathrm{~N} / \mathrm{mm}^{3} \text { (Initial embedment stiffness) } \\
& k_{90}=11.46 \mathrm{~N} / \mathrm{mm}^{3} \text { (Initial embedment stiffness) }
\end{aligned}
$$

The other values indicated in Fig.4 are as follows;

$$
\begin{aligned}
& \alpha_{0}=0.48=k_{0}, / k_{0} \\
& \alpha_{90}=0.61=k_{90}, / k_{90} \\
& \beta_{0}=0.01=k_{0} ” / k_{0} \\
& \beta_{90}=0.05=k_{90} " / k_{0} \\
& \sigma_{10}=20.88 \mathrm{~N} / \mathrm{mm}^{2} \text { (Proportional limit embedment strength) } \\
& \sigma_{190}=9.1 \mathrm{~N} / \mathrm{mm}^{2} \text { (Proportional limit embedment strength) } \\
& \sigma_{\mathrm{y} 0}=28.04 \mathrm{~N} / \mathrm{mm}^{2} \text { (Yield embedment strength) } \\
& \sigma_{\mathrm{y} 90}=12.40 \mathrm{~N} / \mathrm{mm}^{2} \text { (Yield limit embedment strength) }
\end{aligned}
$$

For the $\theta^{\circ}$ direction loading, we used the Hankinson's equation to obtain $k_{\theta}$, $\alpha_{\theta}, \beta_{\theta}, \sigma_{\mathrm{l \theta}}, \sigma_{\mathrm{y} \theta}, k_{\theta+90}, \alpha_{\theta+90}, \beta_{\theta+90}, \sigma_{\mathrm{l} \theta+90}$, and, $\sigma_{\mathrm{y} \theta+90}$.

Static load increment analysis was performed to get the stiffness and P- $\delta$ curve with RBSM. Number of rigid beam element is 38. The software SNAP LE Ver.6 was used for the analysis. To perform this analysis on the software, we dared to use improved model (Fig.5(c)). 

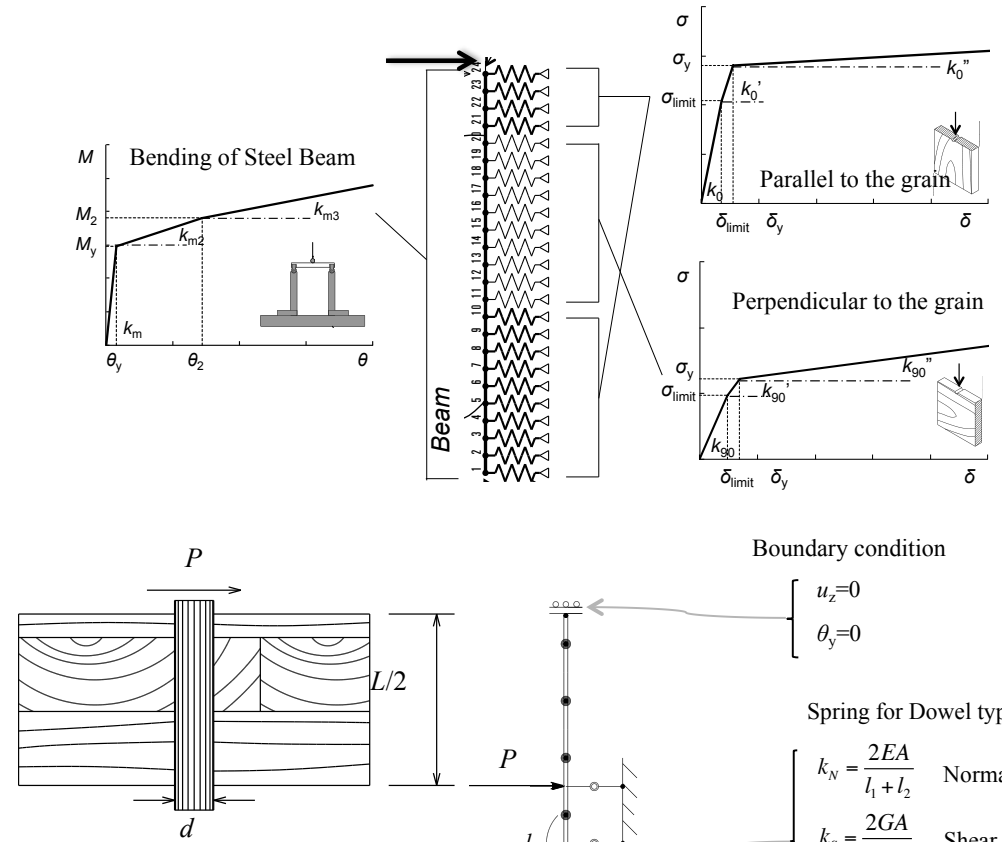

Material properties of steel beam

Diameter

Timber width

Young's Modulus

Shear Modulus

Area

Morment of Inertia

Element length

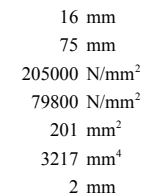

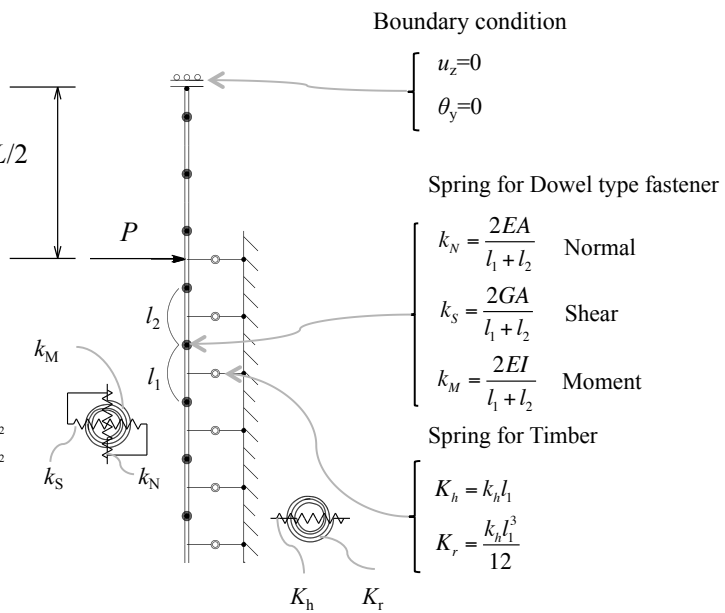

Fig.4 Numerical Analysis Model (RBSM) for the half of the drift pin joint.

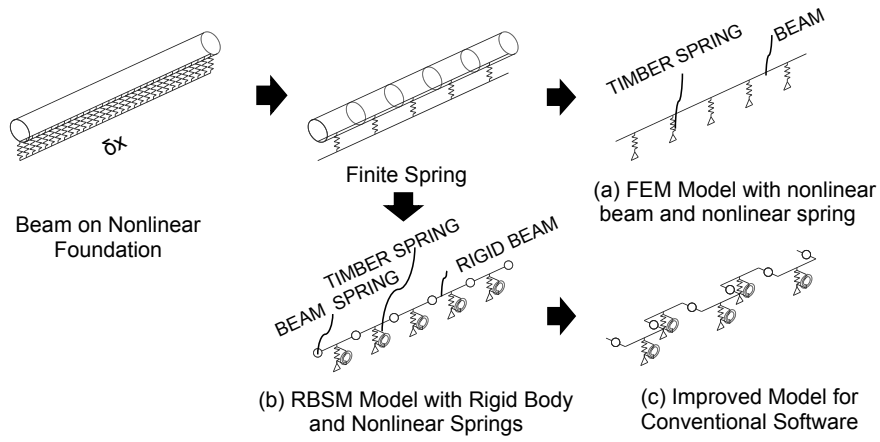

Fig.5 Comparing between FEM model and RBSM model. 


\section{Experiment}

\section{Test Specimen and Materials}

Fig.6 shows the specimens and apparatus for tensile test of joint. Five layered Japanese cedar CLT (thickness of lamina $(t)=30 \mathrm{~mm}$, air-dried specific density $(\rho)=0.43$, moisture contents $(M . C$. $)=13 \%$, all surface of lamina were glued by AIP. ) were used as specimens. The parameters were the angle of the grain direction of outer layer with respect to the loading direction $0^{\circ}, 45^{\circ}$, and $90^{\circ}$. The specimen consists of CLT, steel plate (thickness $t_{\mathrm{s}}=9 \mathrm{~mm}$ ), and drift pin (diameter $(d)$ $=16 \mathrm{~mm})$. The thickness of slit in CLT was $11 \mathrm{~mm}$, then end and edge distances of joints were $7 d$ respectively. Loading protocol used was monotonic and cyclic, and, tensile load and relative displacement between steel plate and CLT were measured. The detail of test was same as reference [5].
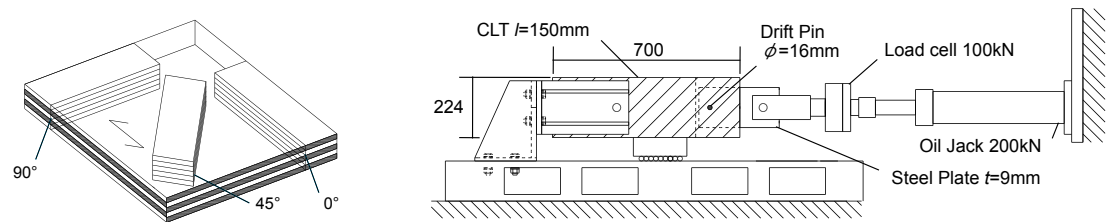

Fig.6 Sampling of specimens and apparatus of tensile test for CLT - drift pin joint.

\section{Results and Discussion}

\section{Comparisons between calculated characteristics and experimentally derived ones}

Fig.7 shows the example of deformation that obtained by analysis. Analysis were performed for half of the figure and copied with turn over. Fig.8 shows Load $(P)$ - deformation $(\delta)$ curve. Left side figures show calculated results and the right side are experimental ones.

Deformations (a) and (b) were Mode2.2 in Fig.3. We can say that the theoretical model estimated deformation curve and $P-\delta$ curves suitably ash shown in Fig.7 and Fig.8.

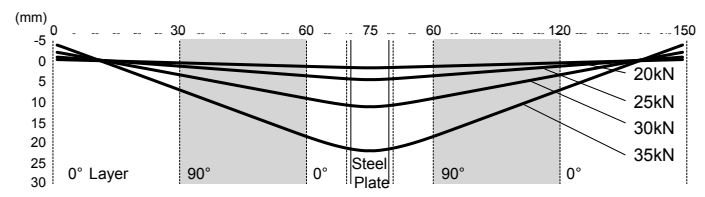

(a) Analysis

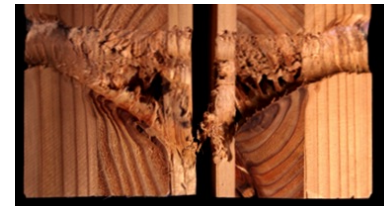

(b) Experiment 
Fig.7 Example of deformation that obtained by analysis and experiment. (Five layered CLT, diameter of drift pin $=16 \mathrm{~mm}$, thickness of layers $=30 \mathrm{~mm}$ )

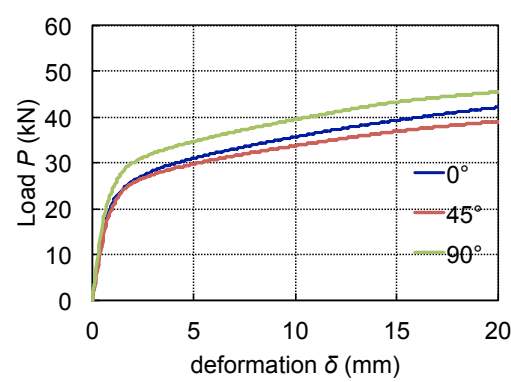

(a) Analysis

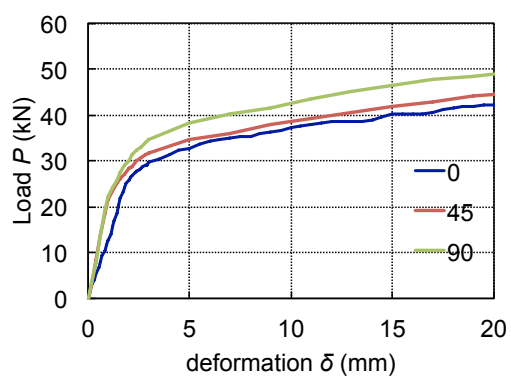

(b)Mean curves of experiments

Fig.8 Example of $\boldsymbol{P}-\delta$ curves that obtained by analysis and experiment.

Fig.9 shows the comparisons between calculated load carrying capacities $\left(p_{\mathrm{y}}\right)$, initial stiffness $(k)$ and experimental values. From these figures, it can be seen that there is satisfactory, agreement between calculated stiffness $(k)$ and experimental ones. While in the case of yielding prediction, some sorts of discrepancy, were observed between calculated load carrying capacity $\left(p_{\mathrm{y}}\right)$ and experimental ones.

The differences according to loading angles of in-plane characteristics are not so much. Especially, the yield load shows almost same values in both calculation and experimental data.

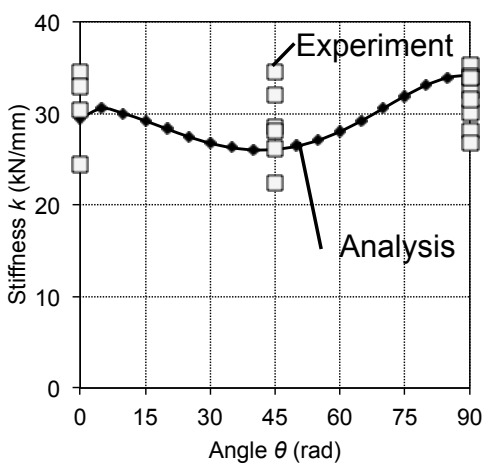

(a) Initial Stiffnes $(k)$

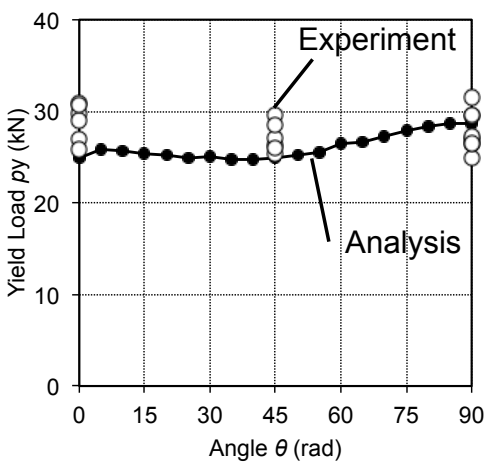

(b) Yield Load $\left(P_{\mathrm{y}}\right)$

Fig.9 Comparison in characteristics between analysis and experiment. 


\section{Conclusion}

Load carrying capacity of drift-pined joint in CLT is derived using the diameter $(d)$, length $(l)$ and bending strength $(F)$ of drift pin and density $(\rho)$ of timber as the parameters for prediction.

Load - deformation curves were determined by the numerical analysis by RBSModel using a commercial computer software. Calculation showed the good agreement with test results.

The differences of mechanical performances according to loading angles of inplane characteristics are not so much. Especially, the yield load shows almost same values in both calculation and experimental data. This indicates that CLT drift-pin joint has very weal orthotropic strength property.

\section{Reference}

[1] Kuenzi E.W.: Theoretical Design of Nailed or Bolted Joint Under Lateral Load, USDA, No. D1951, March 1955

[2] Masamichi Harada: On Longitudinal Strength of Wooden Ships, Report of The Institute of Industrial Science University of Tokyo, Vol.2, No.3 1951 (in Japanese)

[3] H.J.Blaß, Th.Uibel: Forschung an der Universtät Karlsruhe - Stiftförmige Verbindungsmittel in Brettsperrholz, Granzer Holzbau-Fachtangung Tagungsband'06 Brettsperrholz, pp.I-1-I-16, 2006 (in German)

[4] Shoichi Nakashima, Akihisa Kitamori, Takuro Mori, Kohei Komatsu: Evaluation of Tensile Performance of Drift Pin Joint of Cross Laminated Timber with Steel Inserted Plate, World Conference on Timber Engineering, pp.417-424, 2012

[5] Shoichi Nakashima, Akihisa Kitamori, Kohei Komatsu: Evaluation of Tensile Performance of Drift Pin Joint with Steel Plateon Cross Laminated Timber, J. Struct. Constr. Eng., AIJ, Vol.78 No.687, 969-975, 2013 (in Japanese)

[6] Tadahiko Kawai, Chang-Neow Chen: A Discrete Element Analysis of Beam Bending Problems Including the Effects of Shear Deformation, Seisan Kenkyu, Vol.30 No.5 pp.7-10, 1978

[7] Tetsuji Tsujino, Norio Takeuchi, Takuro Hirai: Analyses of the Lateral Resistanes of Bolted Joints and Drift Pin Joints in Timver IV. A preliminary study of applying the Rigid Bodies-Spring Models, Mokuzaigakkaishi, Vol.50 No.3. pp.176-182, 2004 (in Japanese) 